\title{
MANIFIESTO POR LA SUPERVIVENCIA
}

\author{
MANIFESTO FOR SURVIVAL
}

\section{Grupo de estudiantes de Ecología Humana de la Universidad Autónoma de Madrid (España) \\ geeh@uam.es}

\section{CURRÍCULUM VITAE}

Movimiento Humanista la fuerza de la no violencia. Grupo formado por alumnos de quinto curso de la Licenciatura en Biología de la Universidad Autónoma de Madrid. No tiene relación alguna con ningún grupo mediático, político o económico ni limitaciones impuestas por ninguna jerarquía académica. Sólo pretenden concienciar de la situación del Planeta.

\section{RESUMEN}

El cambio climático es la modificación del clima con respecto al historial climático a escala global. Tales cambios se refieren a temperatura, presión atmosférica, precipitaciones o nubosidad, entre otros. En principio se produce por causas naturales, pero también influye la acción humana. El mensaje lanzado por los medios de comunicación es difuso y eso ha conllevado la escasa percepción que tiene la sociedad del verdadero problema que esto supone. De ahí la elaboración de este manifiesto a partir de la recopilación de datos. 


\title{
PALABRAS CLAVE
}

Cambio Climático - Medios de Comunicación - Percepción - Tierra - Atmósfera

\begin{abstract}
Climate change is the change of climate with respect to global climate history. Such changes include temperature, atmospheric pressure, rainfall and cloud cover, among others. Initially produced by natural causes, but also influences human action. The message sent by the media is diffuse and that has led to the poor perception of the real problem of society that this entails. Hence the development of this apparent from the data collection.
\end{abstract}

\section{KEY WORDS}

Climate Change - Media - Perception - Land - Atmosphere

\section{TEXTO:}

Este texto ha sido el resultado de un intenso trabajo de recopilación de datos, de un debate de ideas y de un amplio consenso logrado entre alumnos de quinto curso de la Licenciatura en Biología que se imparte en la Universidad Autónoma de Madrid. Como se puede suponer, la intención de este manifiesto no tiene ninguna causa interesada ni un ánimo de sembrar la inquietud. Ninguno de ellos tiene relación alguna con ningún grupo mediático, político o económico, ni limitaciones impuestas por ninguna jerarquía académica, por lo que cuanto escriben proviene tan sólo de su 
vocación por difundir una información que entienden necesaria sobre un gravísimo problema, que nos atañe muy de cerca, desde un punto de vista basado en datos científicos.

El cambio climático es ya más un hecho constatado que una teoría. Este fenómeno ha alcanzado gran resonancia en los medios de comunicación en los últimos años, sin embargo, la fragmentación de la información, el escepticismo y la creación de intereses cruzados han creado un clima de confusión general que afecta a la percepción de la gravedad de esta crisis inminente.

Los medios de comunicación ofrecen a diario noticias sobre el cambio climático, si bien éstas presentan, muchas veces, una información puntual, a veces contradictoria, vagamente desarrollada y ampliamente desligada. Por otra parte, la difusión general y no especializada sobre el tema parece permitir que cualquier persona, sin importar su formación o sus conocimientos reales sobre este fenómeno, pueda pronunciarse de forma aparentemente consistente y válida. Así pues, es extremadamente frecuente oír tesis infundadas a personajes públicos sin ningún tipo de formación científica, provenientes del mundo de la política, la economía, el periodismo o la televisión, relegando los datos y estudios científicos al mismo nivel que estas opiniones subjetivas.

Como consecuencia, la percepción del verdadero problema queda minimizada para muchas personas que no observan en los pequeños cambios producidos en su entorno inmediato ningún síntoma preocupante.

En el ámbito de la difusión de los datos sobre este problema hay también factores que favorecen la inconsistencia de la información acerca del cambio climático y sus consecuencias. En primer lugar, parece existir una confusión generalizada entre los 
ecólogos (científicos que se dedican al estudio empírico de la dinámica global y local de los ecosistemas) y los ecologistas (activistas, con o sin formación, que defienden el cuidado de la naturaleza incondicionalmente) dando a su vez el mismo valor a los actos y tesis de ambos, reduciendo al nivel de activismo exaltado y desmereciendo la credibilidad de los datos y conclusiones puramente científicas y demostrables de los ecólogos. Por otra parte, algunos científicos corruptos, cuyos nombres han sido recientemente revelados por la Academia de Ciencias Británica, han sido sobornados por las grandes empresas petroleras y de otros sectores, para tergiversar u ocultar datos, así como emitir tesis en contra del calentamiento global con el fin de mantener su producción y sus beneficios aún a costa de seguir promocionando esta catástrofe. El cambio climático, lejos de ser considerado con la seriedad que se merece, se ha convertido en una carta más a jugar en la economía mundial. Ignorado o subvalorado por unos y visto como un negocio a explotar por otros, el cambio climático es contemplado bajo un peligroso prisma empresarial.

Este tratamiento de la información da lugar a una confusión general que es acentuada por el estudio discreto de los efectos que produce y producirá el cambio climático, en vez de un análisis global y generalizado, y que no permite una concienciación seria y realista del fenómeno que nos acontece. La Tierra es un sistema extremadamente complejo en el que se dan simultáneamente una enorme cantidad de procesos altamente interrelacionados y la variación drástica de la dinámica de uno o varios de estos factores puede repercutir, como de hecho ya está ocurriendo, en el funcionamiento general del ecosistema global, con catastróficas consecuencias para los seres humanos.

El calentamiento global es consecuencia de un aumento considerable en el nivel de $\mathrm{CO} 2 \mathrm{y}$ otros gases producidos, fundamentalmente, aunque no únicamente, durante la quema de combustibles fósiles en la atmósfera terrestre. Como ya está 
suficientemente comprobado, este incremento de concentración ha producido un aumento en el efecto invernadero de nuestro planeta y la consecuente subida de las temperaturas medias anuales en todo el globo y acidificando las aguas oceánicas al difundirse el CO2 como ácido carbónico. Este cambio en la temperatura está ligado a la aparición de otros fenómenos subyacentes que se retroalimentan provocando una desestructuración general de la dinámica ecológica de nuestro planeta y los seres vivos que lo habitamos.

Así pues, el aumento de las temperaturas tiene consecuencias visibles directas sobre el derretimiento anormal y acelerado de los casquetes polares y otras masas heladas, si bien en pocas ocasiones se plantean los graves problemas que a su vez conlleva éste hecho. Al derretirse estas enormes masas de hielo se liberan al mar millones de litros de agua dulce y de muy baja temperatura, provocando un aumento inmediato del nivel del mar, lo que inundará zonas costeras y tierras por debajo su nivel actual (como los Países Bajos, por ejemplo), pero también modificando las corrientes oceánicas actuales afectando seriamente a los ecosistemas marinos de los que depende la pesca mundial y modificando los patrones climáticos dependientes de los casquetes polares, resecando el aire y desertizando amplios territorios.

Pero no todo el hielo está en los casquetes polares, según publicó recientemente Gabrielle Walker en la prestigiosa revista Nature, el permafrost del ártico, extensa capa de tierra permanentemente helada y extremadamente rica en materia orgánica, está derritiéndose de forma acelerada, lo que puede dar lugar al liberación masiva de una cantidad de metano comparable a la ya presente en la atmósfera. Este aumento desmesurado en la concentración de gas invernadero retroalimentará los efectos del calentamiento global acelerando su ritmo y extremando sus consecuencias. 
Por otro lado, se ha estimado que el aumento de tan sólo dos grados en la temperatura media global será suficiente para reducir en un $60 \%$ la producción mundial de cereales y así como más gravemente la de otras plantas cultivables. Los cereales son la base de la alimentación humana y del ganado que producimos, lo que irremediablemente desembocará en una crisis alimentaria a escala mundial. Este deterioro en la capacidad de producción, así como la reducción de las tierras habitables por la trasgresión marina y la desertización, y la acentuación de las desigualdades económicas y sociales aumentarán de forma desorbitada las migraciones humanas en situaciones desesperadas (y no sólo en los países pobres), fomentando un clima de conflicto inminente.

La destrucción generalizada de los hábitats naturales promueve además la extinción masiva y abrupta de gran cantidad de especies, desestabilizando la gran complejidad biológica de los ecosistemas. Este hecho, tenido generalmente en baja consideración, es de una gran importancia, pues los recientes estudios sobre la integridad ecológica revelan que estos sistemas son extremadamente complejos y regidos por las interacciones estabilizantes de todos sus componentes, y muy especialmente de una inabarcable cantidad y variedad de virus y bacterias. Estos microorganismos son los más abundantes de todos los seres existentes en la Naturaleza y están presentes en todos los sistemas biológicos y ecológicos. Según estudios publicados en Nature, por cada litro de agua marina hay cerca de 1010 virus y 109 bacterias que regulan la base nutricional de la que dependen todos los organismos acuáticos (incluidas las especies de pesca habitual) e incluso influyen en los ciclos geoquímicos como la descomposición orgánica, la asimilación del nitrógeno y el azufre en los vegetales o la formación de las nubes. Los estudios en otros ambientes, como el suelo o el hielo ártico, revelan resultados similares en cuanto a variabilidad, importancia y abundancia. Pero estos microorganismos, pese a desempeñar un papel imprescindible en los sistemas equilibrados, son susceptibles a los cambios en la 
dinámica del planeta, y una variación en la capacidad infectiva o en la dinámica normal de los mismos puede tener consecuencias catastróficas en el desequilibrio de los ecosistemas y la malignización de estos microbios. Existen estudios, constatados y publicados en revistas especializadas, que prueban que los cambios en la temperatura global afectan a estos y otros microorganismos potenciando la aparición y el efecto de enfermedades que están llevando a la extinción de especies por medio de epidemias impulsadas por el cambio climático. Los seres humanos, como seres vivos que somos, ya estamos potencialmente expuestos a las enfermedades emergentes y a los cambios en la distribución de aquellas infecciones que actualmente se restringen a regiones específicas, pero este fenómeno puede conducir, además, a la aparición de nuevas plagas.

Además, la desaparición de especies desorganiza las complejas redes de nutrición de los ecosistemas equilibrados, permitiendo el desarrollo desmesurado de especies de invertebrados y microorganismos susceptibles a convertirse en plagas para los seres humanos y para los cultivos, acentuando la previsible grave situación de los mismos. De forma análoga, los arrecifes de coral, en los que se condensa gran parte de la biodiversidad marina, están sufriendo severamente los aumentos en la temperatura y acidez del océano, desapareciendo de forma drástica la base de estos ecosistemas esenciales para la integridad de los océanos, pero también para la alimentación y la vida humana. Según expuso Camilo Mora, de la Dalhousie University en Canadá, a la revista Science: "los arrecifes generan cerca de 30.000 millones de dólares al año en pesca, turismo y protección de las costas ante las tormentas marinas" y "albergan a 9 millones de especies - un tercio de todas las formas de vida conocidas".

Pero el problema es aún más complejo. El nivel de $\mathrm{CO} 2$ en la atmósfera es regulado de forma natural por los procesos fotosintéticos de los vegetales, muy especialmente en la extensa selva amazónica. Sin embargo, la exhaustiva actividad de deforestación 
que se está llevando a cabo en la Amazonía y otras selvas con fines únicamente comerciales está disminuyendo de forma radical la extensión de este ecosistema que alberga a la mayor parte de la biodiversidad terrestre, ejerce un efecto de filtro sobre el gas invernadero y es un generador mundial del oxígeno que respiramos. La destrucción de la selva conlleva grandes repercusiones sobre la vida en la Tierra y el interés por su conservación no tiene nada que ver con salvaguardar la existencia de especies exóticas por fines morales o humanistas, sino que su erradicación compromete seriamente la calidad de vida e incluso la supervivencia de la misma, destruyendo la mayor fuente de oxígeno del planeta, favoreciendo la acentuación de la oscilación de las temperaturas, modificando la dinámica hídrica de todo el globo y desestabilizando un complejo ecosistema del que pueden emerger diversas enfermedades y plagas.

Muchos de los problemas que hemos mencionado, y algunos más, son conocidos y difundidos constantemente, pero hay dos conceptos sobre los cuales no se habla suficientemente: El primero es el de "retroalimentación". Entre todos los fenómenos naturales mencionados existe una compleja red de interacciones sujetas a procesos de retroalimentación positiva (efectos derivados de un fenómeno que, a su vez, lo aceleran) y negativa (que lo mitigan), pero el desequilibrio creado por las actividades humanas ha potenciado los procesos de retroalimentación positiva. Algunos son muy evidentes, como el hecho de que la disminución de la superficie helada reduce la capacidad de reflejar el calor del sol, con lo que se acelera el calentamiento que, a su vez, acelera el proceso, pero hay muchos otros, menos intuitivos, pero de una importancia semejante, como la saturación de las aguas marinas en su capacidad de absorber $\mathrm{CO} 2$, el hecho de que el agua menos salinizada se calienta y evapora más rápidamente produciendo vapor de agua, también con efecto invernadero, y unos cuantos más, también de origen antrópico, cuyas consecuencias son una aceleración progresiva del calentamiento global. Y el proceso ya está desencadenado. 
El segundo, es que los fenómenos ecológicos siguen la dinámica de los "sistemas complejos", en la que todos sus componentes están íntimamente interrelacionados y en los que una alteración del equilibrio tiene consecuencias en todo el sistema que no son proporcionales a dicha alteración. Es lo que se conoce como "relaciones no lineales".

Los sistemas complejos se caracterizan por una gran capacidad de ajuste a las alteraciones, pero llegados a un punto de desequilibrio extremo, la consecuencia es un colapso catastrófico.

Ante este desesperante panorama, probablemente más cercano de lo que comúnmente se cree, es necesario buscar soluciones inmediatas y efectivas. Es más, todos los esfuerzos de la Humanidad deberían estar encaminados en esta tarea. Sin embargo, en lo que parece un intento por conservar la forma de vida actual de los países ricos y el sistema socioeconómico imperante, lo que, a modo de anestesia mental, llega a la población, son las ideas de determinados científicos (o científicos de determinados países) que tratan de teorizar soluciones tecnológicas basadas en un remarcable e inadmisible reduccionismo científico y en la completa incomprensión del ecosistema terrestre y del cambio climático como fenómenos de alta complejidad de interacción.

Entre estas soluciones encontramos ideas tecnológicas que, si bien seducen al público general con su aspecto sacado de las novelas de ciencia ficción, se basan en una visión mecanicista de la vida en la que los factores se pueden modificar individualmente y no se retroalimentan (lo cual es claramente erróneo) y son absolutamente dominables y comprensibles para el hombre (lo que también es falso y necio): bombardeo de la atmósfera con gases de azufre, puesta en órbita de filtros y 
espejos solares, creación de "árboles" artificiales, desarrollo de productos transgénicos... Todas estas "soluciones" son claramente ilusorias respecto a su viabilidad y sólo provocarían aún más efectos nocivos como la intoxicación de la atmósfera, cambios en la dinámica climática, descenso de la capacidad fotosintética de los vegetales, contaminación biológica... Sin embargo, parece que la solución tecnológica más tenida en consideración es la vuelta a la energía nuclear como fuente energética no productora de gases invernadero. Como es ampliamente conocido, la energía nuclear genera residuos radiactivos altamente nocivos para la vida, que no se pueden reciclar ni eliminar de ninguna forma conocida. Los residuos nucleares son almacenados en barriles y enterrados en estructuras subterráneas o submarinas, con la vaga esperanza de que cuando salgan al exterior haya transcurrido suficiente tiempo para no tener que buscar culpables. Estos residuos se almacenan en países del tercer mundo bajo la falsa excusa de que no provocarán ningún daño a la población, pero lo cierto es que si la seguridad fuese absoluta nadie se molestaría en exportar estos productos tóxicos a países subdesarrollados. Las fugas radiactivas ya ocurrieron en el pasado con el auge de esta tecnología y sus efectos fueros catastróficos, prolongándose durante generaciones. Y todo esto, sin contar con la posibilidad de accidentes o ataques premeditados.

Por otro lado están las llamadas energías renovables o ecológicas. Estas fuentes de energía (solar, eólica, hidráulica, biocombustibles, etc.) presentan ciertos problemas con respecto a su instalación e impacto sobre el medio, pero su mayor limitación es que no son capaces de generar tanta energía como los combustibles fósiles, por lo que su utilización aislada no permitiría el mantenimiento del consumo energético actual ni del mercado vinculado a éste.

Los más prestigiosos (y galardonados) "profetas del cambio climático" culpan de esta situación "al ser humano" en abstracto, y promueven soluciones basadas en la actitud 
individual ("Qué debo hacer para luchar contra el cambio climático") y soluciones tecnológicas en las que muchas empresas "pioneras" ven una nueva y enorme fuente de ingresos. Pero si algo está claro es que la única solución para hacer frente a la tremenda crisis que se avecina no pasa por reforzar la tecnología y la economía, sino en arrancar de raíz la fuente del problema. El cambio climático es, única y exclusivamente, producto del modelo socioeconómico actual, su desarrollo desorbitado a partir de la revolución industrial y el apoyo científico a su práctica a lo largo de los últimos doscientos años. La explotación indiscriminada de los recursos naturales, y la repartición extremadamente desigual de la riqueza, que sitúa al 99\% de la población bajo las decisiones de unas pocas personas y entidades, la irreflexión sobre los avances tecnológicos y la contaminación y el agotamiento de todas las fuentes naturales son las condiciones necesarias para la supervivencia de un modelo socioeconómico que basa el supuesto bienestar humano en el aumento constante y creciente de la riqueza económica de unos pocos, aunque irremediablemente provoque el empobrecimiento de la calidad de vida ambiental y social del resto del planeta. La amplia liberalización de las operaciones privadas y la ausencia de control sobre ellas o, en otras palabras, la transferencia de decisiones económicas desde un campo, al menos, supuestamente, bajo control democrático (gubernamental) a uno carente del mismo (privado), hace que los modos de producción y de movimientos de capital se configuren a escala planetaria, mientras los gobiernos van perdiendo atribuciones ante lo que se ha denominado la "sociedad en red" (la red de los poderosos) cuyo único interés son sus crecientes beneficios. La búsqueda de soluciones tecnológicas irreales se basa en la intención de mantener este sistema socioeconómico intacto como base del desarrollo humano, si bien es más que evidente que es este desarrollo neocapitalista el que nos ha llevado a la crítica situación actual. Por lo tanto, la solución lógica pasa por la concienciación de la verdadera gravedad de este problema al público general (que es la finalidad de este texto) y a los dignatarios que nos gobiernan, realizar análisis complejos e 
integradores para prever las consecuencias y paliar coherentemente sus efectos, pero, sobre todo, aplicar un inmediato cambio hacia un modelo socioeconómico que no comprometa la existencia del Hombre sobre la Tierra.

No se trata de una propuesta utópica o candorosa. Somos conscientes de que si los máximos responsables de esta desesperada situación no han cambiado su actitud depredadora a pesar de que pueden ver diariamente los rostros de sus víctimas, no van a hacerlo pensando en las generaciones futuras. Se trata de dejar constancia de que las verdaderas causas de este problema son evidentes y de que no habrá solución si no se hace frente a ellas.

Tratar de conservar la tierra para las generaciones futuras ha sido siempre una de las metas del hombre en todos los pueblos del mundo. Al ser olvidada esta obligación moral durante más de tres siglos de desarrollo insostenible e irracional, ahora nos veremos obligados a luchar duramente por conservar la esperanza para la vida. 